\title{
An Extensive Review on the Relationship between Food and Mood
}

\author{
Shreyasi Halder ${ }^{1}$, Kazi Layla Khaled ${ }^{2}$ \\ ${ }^{1,2}$ University of Calcutta, Department of Home Science, 20B Judges Court Road, Kolkata-700027, India
}

\begin{abstract}
Food and mood are regular consistent part of our lives and they inevitably get tangled up together. This review study aims to find out the physiochemical and biochemical relationships and the exact mechanism that binds food with mood. Results showed that caffeine improves vigilance, alertness, mood and cognitive processes during and after exercise. L-theanine a major component of tea, has anxiolytic and calming effect due to its up-regulation of inhibitory neurotransmitters and possible modulation of serotonin and dopamine in selected areas. Antidepressant-like effect of chocolate can most likely be attributed to the antioxidant potential of cocoa polyphenol which reduces hunger and elevates mood.n-3 PUFA present in fish oil exerts anti-depressant effect. Folic acid and Vitamin $C$ is beneficial for the reduction of Childhood Depression.
\end{abstract}

Keywords: food, mood, caffeine, L-theanine, neurotransmitters

\section{Introduction}

Hippocrates the father of modern medicine, once said: "Let your food be your medicine and your medicine be your food." Studies suggest that foods directly influencing brain neurotransmitter systems have the greatest effects on mood. In turn, mood can also influence our food choices and expectations on the effects of certain foods can influence our perception ${ }^{[1]}$

The mood-food relationship describes how mood may influence a person's food choices. People grab a cup of coffee to give them a boost if they are feeling tired or irritable $^{[2]}$. Healthy foods, such as fruits, vegetables, fish, nuts and seeds, help to promote cheerfulness, satisfaction and happiness. Other foods may boost negative feelings, such as anger, frustration, tension, or anxiety. Feelings of sadness are sometimes accompanied by a craving for comfort foods, often rich in salt or sugar, or alcohol ${ }^{[3]}$.

Research on the relationships between food and mood is ongoing. However, there are several theories on how and why food affects mood. One such theory is related to the impact of sugar on blood sugar. Because blood sugar can affect energy and mood, it is thought that ingesting sugar can influence mood. Another theory concerns brain chemicals such as serotonin and dopamine. These are known to directly affect mood and feelings, and they may be influenced by the food a person ingests. Other researchers are studying human reactions to artificial food colouring and flavours and sensitivities to certain foods, like dairy and gluten ${ }^{[4]}$.

There are many explanations for the cause-and-effect relationship between food and mood. The following are some examples:

1) Fluctuations in blood sugar levels are associated with changes in mood and energy, and are affected by what we eat.

2) Brain chemicals (neurotransmitters, such as serotonin, dopamine and acetylcholine) can be affected by what we've eaten.
3) Links have been demonstrated between low levels of certain B-vitamins and symptoms of schizophrenia, low levels of the mineral zinc and eating disorders, and low levels of omega-3 oils and depression.

4) Size of the meal: Large amount of fat slows down absorption and because blood flow to the stomach is increased for a longer period of time, resulting in less blood flow to the brain resulting in sleepiness and sluggishness.

\subsection{Effect of neurotransmitters on food intake}

The two important brain chemicals that are influenced by foods, dopamine and norepinephrine, produce a feeling of alertness, an increased ability to concentrate, and faster reaction times. There are two possible mechanisms for how this happens: (1) serotonin production is blocked by the consumption of protein-rich foods, resulting in increased alertness, or (2) levels of dopamine and nor epinephrine are increased by the consumption of protein-rich foods ${ }^{[61]}$.

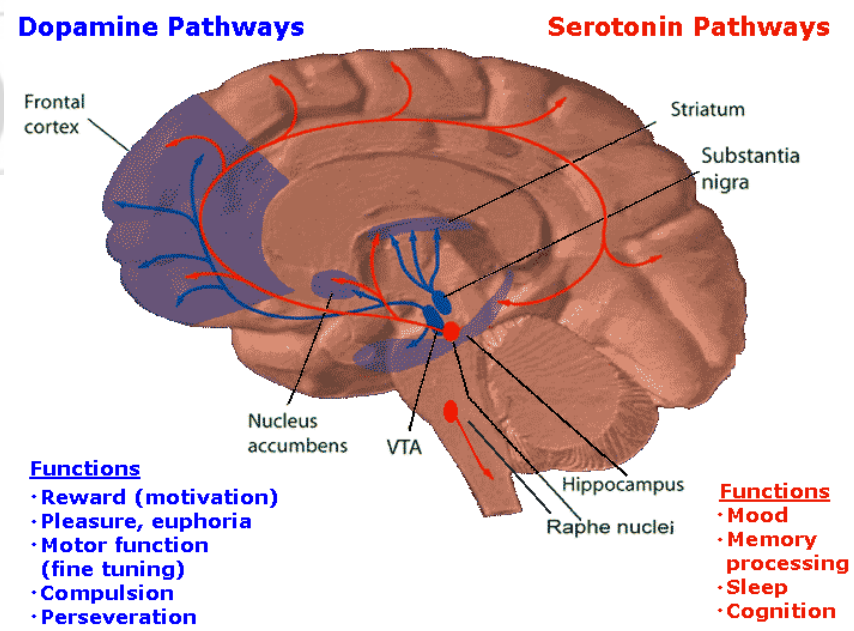

Figure 2: Serotonin dopamine pathway ${ }^{[62]}$

\subsection{Yin Yang Scale of Food and Mood}

Stress is one of the characteristics of a body that is excessively yang. Therefore, the body leans towards foods 


\section{International Journal of Science and Research (IJSR) \\ ISSN (Online): 2319-7064}

Index Copernicus Value (2013): 6.14 | Impact Factor (2015): 6.391

that are neutral or yin in nature to balance out the excess yang. If the body is seriously imbalanced, then it will crave for things on the other extreme of the scale. Eating foods from either extreme (see chart below) can cause mood swings and make us feel off balance. ${ }^{[60]}$

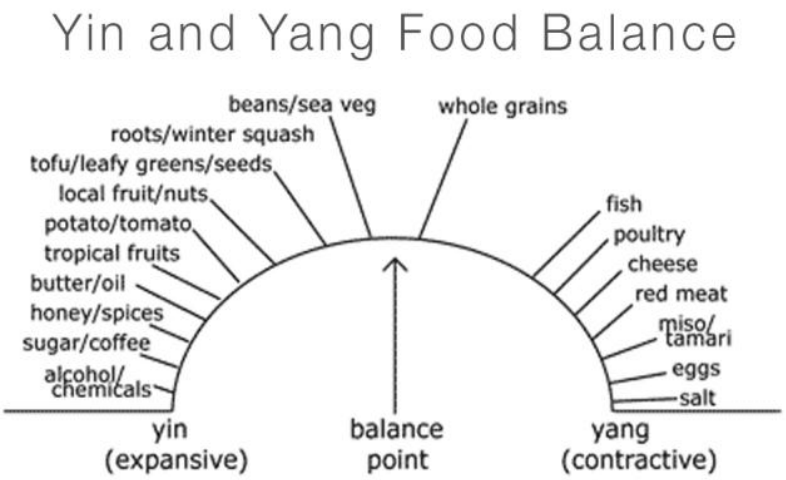

Figure 1: The yin yang chart ${ }^{[60]}$

\section{Aims and Objectives}

Like the chicken-and-the-egg situation, which came first, the food or the mood? Do the moods hatch the foods, or do the foods hatch the moods?

Studies disagree - the relationship seems to go both ways. A couple of recent studies suggest that the foods come first. Both eating and emotion are such regular, consistent parts of our lives that it's inevitable they would get tangled up together ${ }^{[5]}$

Some of the basic foods that most of us consume everyday like tea, coffee, fish, green vegetables etc. are amazing mood boosters but on the other hand if we consume excess of coffee and tea it can act as mood depressors. The relationship between food and mood is complex and depends on the time of day, the type and macronutrient composition of food, the amount of food consumed and the age and dietary history of the subject ${ }^{[6]}$. These simple relationships have been dealt in this project in much detail.

\section{Review of Literature}

\subsection{The effect of tea on mood}

Rao et.al.(2015) have shown that 1-Theanine promotes relaxation without drowsiness. 1-theanine is not a sedative but promotes good quality of sleep through anxiolysis which confirms that 1-theanine is a safe natural sleep aid ${ }^{[7]}$. Lardner et al.(2014) confirms that theanine has anxioltic and calming effect due to its up-regulation of inhibitory neurotransmitters and possible modulation of serotonin and dopamine in selected areas ${ }^{[8]}$.Verma (2014) states that theanine present in tea affects serotonin and dopamine in the brain,

neurotransmitters that give rise to a calm, happy and tranquil feeling. Theanine also provides relief of PMS symptoms, blood pressure regulation and enhancement of memory and concentration $^{[9]}$. Kimura et.al (2007) showed that LTheanine intake resulted in a reduction in the heart rate (HR) and salivary immunoglobulin $\mathrm{A}(\mathrm{s}-\operatorname{Ig} \mathrm{A})$ responses to an acute stress condition ${ }^{[10]}$.

Bryan et al.(2008) suggests that caffeinated tea when ingested at regular intervals may maintain alertness, focused attention accuracy and may modulate the more acute effects of higher doses of caffeine ${ }^{[11]}$

Fennel Tea stabilizes glucose levels which helps prevent mood swings and helps boost serotonin and endorphin levels ${ }^{[12]}$.

\subsection{Coffee for our mood}

As a mood enhancer, coffee is one of the safest and fastest agents on earth. Coffee enhances the flow of blood in the brain and invigorates the mind. It enhances alertness and motivation, facilitates thought formation and concentration, and decreases mental fatigue. A study published in the Archives of Internal Medicine, Harvard states that drinking caffeinated coffee lowered rates of depression among women. Coffee is also referred to as the "pleasure drug" [13]. Caffeine strongly affects the activity of the hypothalamic-pituitary-adrenal (HPA) axis. The HPA axis influences the body's ability to manage and deal with stress, bothat rest and during activity ${ }^{[14]}$. At low doses, caffeine improves hedonic tone and reduces anxiety, while at high doses, there is an increase in tense arousal, including anxiety, nervousness, jitteriness says Nehling et al $(2010)^{[15]}$. Spriet et al(2014) states that low doses of caffeine improve vigilance, alertness, and mood and cognitive processes during and after exercise ${ }^{[16]}$. Roehrs (2008) states that caffeine has profound effects on sleep and wake function. Regular dietary caffeine intake is associated with disturbed sleep and associated daytime sleepiness ${ }^{[17]}$. Smith et al (2005) says that who consumed higher levels of caffeine reported significantly greater increase in alertness over the working day and demonstrated fewer cognitive failures and accidents at work $^{[18]}$. Brice et al.(2001) suggests that caffeine increases alertness and reduces fatigue especially in low arousal situations ${ }^{[19]}$. Coffee has true performance-enhancing effects and at the same time, the existence of significant detrimental effects of caffeine deprivation on psychomotor performance has not been ruled out, confirms Rogers et al.(1995) ${ }^{[20]}$.

\subsection{Chocolate, the mood booster}

"Chocolate causes certain endocrine glands to secrete hormones that affect your feelings and behaviour by making you happy. Therefore, it counteracts depression, in turn reducing the stress of depression. Your stress-free life helps you maintain a youthful disposition, both physically and mentally. So, eat lots of chocolate!" says Elaine Sherman ${ }^{[21]}$. Chocolate contains a variety of substances, some of which have an effect on body chemistry.

These include:

a)Sugar: Chocolate bars (as opposed to cocoa) contain large amounts of sugar.

b)Theo bromine: This is the primary alkaloid found in cocoa and chocolate, and is one of the causes for chocolate's mood-elevating effects.

c) Anandamide: An endogenous cannabinoid.

\section{Volume 5 Issue 5, May 2016}




\section{International Journal of Science and Research (IJSR) \\ ISSN (Online): 2319-7064}

Index Copernicus Value (2013): 6.14 | Impact Factor (2015): 6.391

d)Tryptophan: An essential amino acid that is a precursor to serotonin, an important neurotransmitter involved in regulating moods.

e) Phenethylamine:An endogenous alkaloid and monoamine. Often described as a 'love chemical', it can cause endorphin releases in the brain ${ }^{[22]}$

In a research conducted by Sunni et.al(2014) it was concluded that consumption of $40 \mathrm{~g}$ of Dark and Milk chocolate daily during a period of 2 weeks appear to be an effective way to reduce perceived stress in females ${ }^{[23]}$.

Sokolov et al (2013) found that the absorbed flavonoids present in cocoa beans penetrate and accumulate in the brain regions involved in learning and memory, especially the hippocampus ${ }^{[24]}$. Anxiety increased over time for high chocolate cravers; non deprived high cravers ate the most chocolate; and high cravers were more joyful and guilty than low cravers after eating chocolate in the laboratory ,this was seen in a study conducted by Dominguez et al $(2012)^{[25]}$. James Ferre et al.(2009) indicates that cocoa polyphenols help to reduce the symptoms of depression and this antidepressant-like effect can most likely be attributed to the antioxidant potential of cocoa polyphenols ${ }^{[26]}$. Macht et al(2006) examined the emotional changes after eating chocolate and apple in everyday life. Both chocolate and apple reduced hunger, elevated mood and increased activation but the effects of chocolate were stronger. Eating chocolate was also followed by joy and in some women by guilt ${ }^{[27]}$.

\subsection{Nuts have mood boosting effects}

Nuts are like a miracle drug — something we can take that makes us feel happier, decreases hunger and improves heart health.

A Research done on 22 people with metabolic syndrome on a nut-enriched diet for 12 weeks, it was found that the patients' urine had many healthful changes in those who ate nuts, including increased levels of serotonin ${ }^{[28]}$.

Peanuts provide us with tryptophan which assists our brain to create serotonin, helping us to get a good night's sleep. If peanuts are regularly consumed, the vitamin B6 found in this nut can alleviate the symptoms of pre-menstrual syndrome boosting the strength of the overall immune system.

Research shows that nuts and seeds just might boost our brainpower and balance our moods. Everything from the most common nuts -- such as walnuts, hazelnuts, cashews and almonds -- to the more exotic seeds and nuts can clear up that "brain fog" and enable us to think clearer and be happier ${ }^{[64]}$.
Table 1: Mood boosting nuts ${ }^{[29]-[30]}$

\begin{tabular}{|c|c|c|}
\hline Nut & Composition & Effect on mood \\
\hline Almonds & $\begin{array}{c}\text { Contain B vitamin, } \\
\text { folate and tyrosine, a } \\
\text { precursor to dopamine }\end{array}$ & $\begin{array}{c}\text { Doamine is essential for } \\
\text { motivation. Dopamine } \\
\text { levels are depleted by } \\
\text { stress. }\end{array}$ \\
\hline Cashews & $\begin{array}{c}\text { Packed with soluble } \\
\text { fibre, minerals, vitamins } \\
\text { and numerous } \\
\text { phytochemicals. }\end{array}$ & $\begin{array}{c}\text { Prevent depression, boost } \\
\text { mood and stabilize } \\
\text { thoughts. }\end{array}$ \\
\hline Peanuts & $\begin{array}{c}\text { contain tryptophan, } \\
\text { vitamin B-6 }\end{array}$ & $\begin{array}{c}\text { Tryptophan helps to } \\
\text { stabilise our mood and } \\
\text { help us get a good night's } \\
\text { sleep. Vitamin B-6 } \\
\text { alleviates the symptoms of } \\
\text { pre-menstrual syndrome. }\end{array}$ \\
\hline Walnuts & $\begin{array}{c}\text { one of the richest source } \\
\text { of omega 3 fatty acids }\end{array}$ & $\begin{array}{c}\text { Dubbed as "brain food", } \\
\text { controls mood, walnuts } \\
\text { prevent insomnia, } \\
\text { depression, overeating. }\end{array}$ \\
\hline Brazil-nuts & $\begin{array}{c}\text { Selenium prevents } \\
\text { anxiety, depression, } \\
\text { One of the best source } \\
\text { of selenium }\end{array}$ \\
\hline
\end{tabular}

\subsection{Seeds and oils to enhance our mood}

Ashley Miller (2015) suggests that flax seeds contain emotion-boosting Omega-3 fatty acids. Flaxseed oil, provide a number of benefits for mood and brain functioning ${ }^{[31]}$. At the 2007 annual meeting of the American Psychosomatic Society in Budapest, Hungary Dr. Sarah M. Conklin reported that omega-3 polyunsaturated fatty acids, found in salmon and flax seed may affect parts of the brain related to emotion. ${ }^{[32]}$. Heather Williams suggests Chia seeds are the most powerful source per ounce of omega 3 fatty acids, which are directly linked to beating depression. Chia seeds improve mental focus, mood and concentration ${ }^{[33]}$. Sunflower seeds are rich in vitamin E, selenium, magnesium and also contain tryptophan which promotes relaxation, calm the brain and relieve tension [34]. Pumpkin seeds contain an abundant amount of tryptophan. Just half a cup of pumpkin seeds has almost our entire RDA of magnesium, which is good for helping us relax ${ }^{[35]}$. A single serving of hemp seed contains nearly $50 \%$ of the daily recommended dose of magnesium , which creates a very soothing and relaxing sensation throughout the body ${ }^{[36]}$. Sesames seeds are one of the best vegetarian source of zinc, a mineral that has been linked to depression and anxiety ${ }^{[37]}$. Wheat germ contains phytosterols, that have a positive effect on our outlook and folic acid, which help to fight depression ${ }^{[38]}$. Walnut oil is rich in omega 3 fatty acids which keep stress levels and blood pressure at check ${ }^{[39]}$.

\subsection{Mood elevating herbs and spices}

Hugel et al(2015) considers the the effects of kitchen spices like cinnamon, ginger, rosemary, rosemary, sage, Chinese celery etc. some of which are commonly used herbal combinations and represent highly promising therapeutic natural compounds against Alzheimers Disease ${ }^{[40]}$. 


\section{International Journal of Science and Research (IJSR) \\ ISSN (Online): 2319-7064}

Index Copernicus Value (2013): 6.14 | Impact Factor (2015): 6.391

Moshiri et.al.(2014) showed the effectiveness of saffron as an antidepressant drug. Clinical trials conducted on women with premenstrual syndrome showed that saffron could reduce suffering symptoms more than the placebo and similar to standard treatments ${ }^{[41]}$. Lopresti et.al.(2014) states that saffron's antidepressant effects potentially are due to its serotonergic, antioxidant, anti-inflammatory, neuro-endocrine and neuroprotective effects ${ }^{[42]}$. Akhondzadeh et.al.(2005) conducted a study showing the efficacy of Crocus sativus(saffron) in the treatment of mild to moderate depression $^{[43]}$. Smelling cinnamon can improve brain function and our mood. Basil can be taken for depression and neurosis. Coriander makes us feel happier. By drinking tea with ground cardamom will alleviate depression ${ }^{[44]}$.

\subsection{Emotions and eating}

Collins etal (2015) confirm that memory cue and positive mood exert opposing effects on food consumption ${ }^{[45]}$. Olabi et.al(2015) states that the effect of the diet on mood appeared to be more related to the weight loss than to the effects of diet $^{[46]}$. Food choice is related to mainly positive emotions, suggesting that food-evoked emotions can add to liking ratings in explaining choice behaviour, says Jiang et al(2014) [47]. Gardner et al. (2014) confirms that individuals select healthy or indulgent foods depending on whether they are in a good or a bad mood, respectively. Individuals in positive moods who make healthier food choices are often thinking more about future health benefits than those in negative moods, focuses more on the immediate taste and sensory experience $^{[48]}$

Lemmens et al.(2014) concluded that consumption of a highprotein vs. high-carbohydrate meal appears to have limited impact on stress-related eating behaviour ${ }^{[49]}$.

A study conducted by Evers et al(2013) showed that positive emotions evoked more caloric intake and that snack intake in daily life was reported to result from positive emotions more frequently than from negative emotions ${ }^{[50]}$. Griffiths (2013) suggests that highly anxious people are more likely to turn to food for comfort, leading to excessive eating, and cause themselves more anxiety when this comfort is unavailable ${ }^{[51]}$. Yeomans et al(2009) suggest that restraint alone is a poor predictor of likelihood of overeating in response to stress, and also suggest that positive mood enhances the tendency to overeat ${ }^{[52]}$. Appleton et al(2007) concludes that depressed mood is associated with fish intake both directly, and indirectly as part of a diet that is associated with depression and as part of a lifestyle that is associated with depression ${ }^{[53]}$ .Gibson et.al. (2006) studies the influence of food on mood and emotions and vice versa .Eating a meal will typically reduce arousal and irritability, and increase calmness and positive affect. Unusual meals, e.g. too small, unhealthy may negatively affect mood. Sweetness, and sensory cues to high energy density, can improve mood and mitigate effects of stress ${ }^{[54]}$. Cools et.al(1992) showed that in neutral mood, food intake decreased and in positive/negative mood, food intake increased ${ }^{[55]}$. Meaningful changes in positive affect were observed with the daily consumption of approximately 7-8 servings of fruit or vegetables in a study conducted by White et al (2001) ${ }^{[56]}$.

\subsection{The effect of Depression on food intake}

Gangwisch et al.(2015) hypothized that higher dietary GI and glycemic load would be associated with greater odds of the prevalence and incidence of depression. High-GI diets could be a risk factor for depression in postmenopausal women ${ }^{[57]}$. Mikolajczyk et al.(2009) examined and stated that in females, perceived stress was associated with more frequent consumption of sweets/fast foods. Additionally, depressive symptoms were associated with less frequent consumption of fruits/vegetables and meat ${ }^{[58]}$.Coppen et al. (2005) suggests that both low folate and low vitamin B12 status have been found in studies of depressive patients and in patients with recurrent mood disorders. Oral doses of both folic acid (800 microg daily) and vitamin B12 (1 mg daily) should be tried to improve treatment outcome in depression ${ }^{[59]}$.

\section{Mood, Food and Obesity}

Social and psychological factors of mood, stress, and emotion also play a critical role in food choice. Through neurobiological data, presence of food cravings, over eating, and tolerance support an addiction-like model by numerous signals that are involved in engaging both the central and peripheral nervous system in a bi-directional manner to regulate food intake. This repetitive eating of comfort foods, rich in carbohydrate, high-fats and sugar, leads to obesity. Obesity in turn regulates mood due to metabolic disturbances. Metabolic disturbances further alter brainsignalling systems leading to a bi-directional vicious cycle of mood, food, and obesity ${ }^{[63]}$.

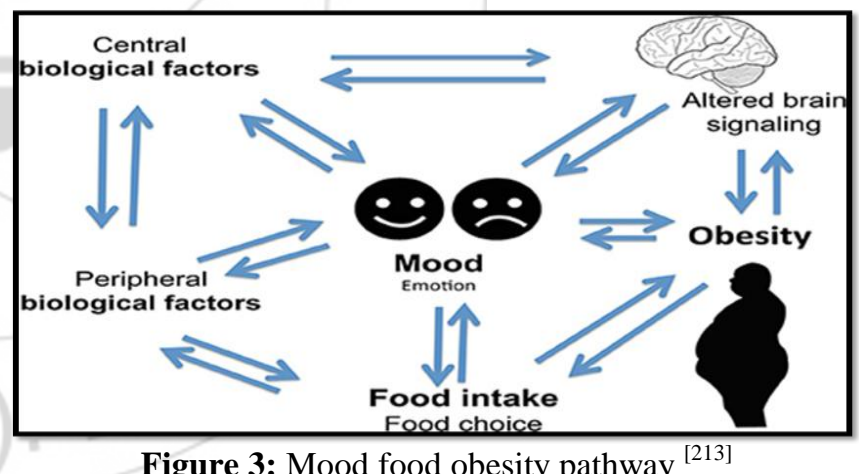

\section{Conclusion}

- L-theanine a major component of tea , has calming effect and it is a safe natural sleep aid, it relaxes our mind and body.

- Low doses of caffeine improves vigilance, alertness, mood and cognitive processes during and after exercise.

- Chocolate reduces hunger, elevates mood and eating chocolate is also followed by joy and, in some women, by guilt.

- In neutral mood, food intake decreased and in positive/negative mood, food intake increased. Sweet carbohydrate/fat rich foods are consumed because of the resulting mood enhancement. Highly anxious people are more likely to turn to food for comfort, leading to excessive eating. 


\section{International Journal of Science and Research (IJSR) \\ ISSN (Online): 2319-7064}

Index Copernicus Value (2013): 6.14 | Impact Factor (2015): 6.391

- Negative mood plays a role in the tendency to overeat. Depressive symptoms were associated with less frequent consumption of fruits/vegetables and meat and high lipid consumption.

- Ethyl-EPA present in coconut oil and soyabean oil has anti-inflammatory, anti-stress and anti-anxiety effects. Chia Seeds supports improved mental focus, mood and concentration. Pumpkins seeds contain health-supportive phytosterols, making it a good anti-depressant. Salmon, flax seeds, walnuts and olive oil also has mood elevating properties.

- Saffron's antidepressant effects potentially are due to its serotonergic, antioxidant, anti-inflammatory, neuroendocrine and neuroprotective effects.

\section{References}

[1] Prasad C, Food, mood and health: a neurobiological outlook, Brazilian Journal of Medical and Biological Research, 31(12): 1517-1527, 1998.

[2] Amber Erickson Gabbey, published on $10^{\text {th }}$ Feb 2014, Medically reviewed by George Krucik, MD,MBA on $10^{\text {th }}$ Feb 2014.

[3] White, B. A., Horwath, C.C., \& Conner, T. S, Many apples a day keep the blues away - daily experiences of negative and positive affect and food consumption in young adult ,British Journal of Health Psychology, 18(4), p. 782-798,2013

[4] Written by Amber Erickson Gabbey,Published on $10^{\text {th }}$ Feb 2014 ,Medically reviewed by George Krucik,MD, MBA on 10th Feb 2014.

[5] Julie Beck ; The Mess Relationship Between How We Feel And What We Eat, March 6,2015

[6] Rogers P.J. \& Lloyd H.M.,Nutrition and mental performance, Proceedings of the Nutrition Society,53 :443-456,1994

[7] Rao TP, Ozeki M, Juneja LR ;In Search of a Safe Natural Sleep Aid.;J Am Coll Nutr.; 1-12., Mar 11,2015 .

[8] Lardner AL.; Neurobiological effects of the green tea constituent theanine and its potential role in the treatment of psychiatric and neurodegenerative disorders, ;Nutr Neurosci. ;17(4):145-55., 2014 Jul.

[9] Dr. Verma; 12 Teas that boost your Mood; The Daily Meal; www.thedailymeal.com; March 24, 2014;

[10] Kimura K , Ozeki M, Juneja LR, Ohira H ;L-Theanine reduces psychological and physiological stress responses.; Biol Psychol. ;74(1):39-45., 2007 Jan

[11] Bryan J ; Psychological effects of dietary components of tea: caffeine and L-theanine ; Nutr Rev. ; 66(2):82-90., $2008 \mathrm{Feb}$

[12] Dr. Verma; 12 Teas that boost your Mood; The Daily Meal; www.thedailymeal.com; March 24, 2014

[13] Chris Nilham, Coffee an effective mood booster; FoxNews.com, Nov 28,2012.

[14] Bryan Walsh; Coffee And Hormones, here's how coffee really affects your health; www.precisionnutrition.com

[15] Nehlig A ;J Alzheimers Dis; Coffee: A cognitive enhancer.; 20 Suppl 1:S85-94.,2010
[16] Spriet LL; Exercise and sport performance with low doses of caffeine; Sports Med.;44 Suppl 2;S175-84. 2014 Nov,

[17] Roehrs T, Roth T; Caffeine: sleep and daytime sleepiness; Sleep Med Rev;12(2); pp-153-62, 2008 Apr

[18] Smith AP ; Caffeine at work; Hum Psychopharmacol. ;20(6); pp-441-445,2005 Aug.

[19] Brice C, Smith A. The effects of caffeine on simulated driving, subjective alertness and sustained attention; Hum Psychopharmacol.; 16(7); pp-523-53. 2001 Oct,

[20] Rogers PJ , Richardson NJ, Dernoncourt C. Caffeine use: is there a net benefit for mood and psychomotor performance? Neuropsychobiology.;31(4):pp-195$199,1995$.

[21] Elaine Sherman, Chocolate Quote- Book of Divine Indulgences; www.montblancgourmet.com;the blend blog

[22] http://en.wikipedia.org/wiki/Chocolate

[23] Al Sunni A, Latif R; Effects of chocolate intake on Perceived Stress; a Controlled Clinical Study; Int J Health Sci (Qassim).; 8(4) ; pp-393-401.; 2014 Oct.

[24] Sokolov AN,Pavloa ,MA Klosterhalfen S,Enck P; Neurosci Biobehav Rev. ;37(10 Pt 2):2445-53;2013 Dec.

[25] Moreno-Dominguez S, Rodríguez-Ruiz S, Martín M, WarrenCS.;Experimental effects of chocolate deprivation on cravings, mood,and consumption in high and low chocolate-cravers; Appetite. ; 58(1); pp-111-6.; 2012 Feb.

[26] James Ferre; Chocolate has anti-depressant qualities: study; February 24, 2009.

[27] Michael Macht' , Dorothee Dettmer; Everyday mood and emotions after eating a chocolate bar or an apple; Appetite; 46( 3); Pp- 332-336.; 2006 May.

[28] Jennipher Walters; http://www.shape.com/blogs; Shape your life/it-really-better-give-receive-study-finds; Nov 11,2011 .

[29] Mila Wood ; http://www.weekendnotes.com; Seeds and nuts to boost your moods; June $14^{\text {th }}, 2013$

[30] Dani Veracity; Research shows that seeds and nuts are "brain foods" that can also stabilize your mood; http://www.naturalnews.com , August 07, 2006.

[31] Ashley Miller; Flax Oil for Mood \& Brain Functions; http://www.livestrong.com; Feb 18, 2015

[32] Japanese Journal of Seishin Shinkeigaku Zasshi; Omega-3 fatty acids in mood disorders. 2005.

[33] Heather Williams; 9 ways to improve mood with food; health.allwomenstalk.com

[34] 7 foods to improve your mood; www.lexiyoga.com

[35] Chloe Johnson; http://food.allwomenstalk.com; 7 Foods That Will Boost Your Mood and Help with Anxiety.

[36] Organic facts; Health Benefits of Hemp Seed; www.organicfacts.net.

[37] Katie Waldeck; 6 Mood-Boosting Foods; A Care2 favourite; http://www.care2.com.

[38] Chelsea Vurciaga; Choose Good Mood Foods; http://wildoats.com; $22^{\text {nd }}$ Aug 2014.

[39] Jessica Migalla; Enhance Your Heart, Mood and Skin With These 4 Edible Oils; It might be time for an oil change. 14 OCT 2014.

[40] Hügel HM ;Brain Food for Alzheimer-Free Ageing: Focus on Herbal Medicines.;863:95-116.;2015

\section{Volume 5 Issue 5, May 2016}




\section{International Journal of Science and Research (IJSR) \\ ISSN (Online): 2319-7064}

Index Copernicus Value (2013): 6.14 | Impact Factor (2015): 6.391

[41] Moshiri M, Vahabzadeh M, Hosseinzadeh H.; Clinical Applications of Saffron (Crocus sativus) and its Constituents: A Review.; Drug Res (Stuttg).;65(6):28795. Jun 2015.

[42] Lopresti AL, Drummond PD. ; Saffron (Crocus sativus) for depression: a systematic review of clinical studies and examination of underlying antidepressant mechanisms of action. ;Hum Psychopharmacol.;29(6):517-27. Nov 2014.

[43] Akhondzadeh S, Tahmacebi-Pour N, Noorbala AA, Amini H, Fallah-Pour H, Jamshidi AH, Khani M.; Phytother Res.Crocus sativus L. in the treatment of mild to moderate depression: a double-blind, randomized and placebo-controlled trial.;19(2):148-51,Feb 2005.

[44] Trace Food to lift your Mood; From an interview with Julie Wood RN, GDHSc(NM), GDHSc(OH); How To Overcome Stress Naturally ;Chapter 5; $5^{\text {th }}$ July 2010

[45] Rebecca Collins, Lorenzo D. Stafford; Feeling happy and thinking about food. Counteractive effects of mood and memory on food consumption; Appetite; Volume 84, Pg: 107-112.,1 Jan 2015.

[46] A. Olabi , D.A. Levitsky, J.B. Hunter, R. Spies, A.P. Rovers, L. Abdouni; Food and mood: A nutritional and mood assessment of a 30-day vegan space diet; Food Quality and Preference; 40(A), Pg:110-115, March 2015.

[47] Y. Jiang, J.M. King', W. Prinyawiwatkul; A review of measurement and relationships between food, eating behaviour and emotion ;Trends in Food Science \& Technology;36( 1), Pg: 15-28.,March 2014.

[48] Meryl P. Gardner', Brian Wansink, Junyong Kim ;Better moods for better eating?: How mood influences food choice; Journal of Consumer Psychology; 24( 3), Pg: 320-335; July 2014

[49] Lemmens SG , Martens EA, Born JM, Martens MJ, Westerterp-Plantenga MS; Lack of effect of highprotein vs. high-carbohydrate meal intake on stressrelated mood and eating behavior ;Front Psychol.;5:925.;Sep 1,2014.

[50] Evers C, Adriaanse M, de Ridder DT, de Witt Huberts ;JCGood mood food; Positive emotion as a neglected trigger for food intake.; Physiol Behav.98(3) pg:318-25; Sep 7,2009;

[51] Mark D. Griffiths Ph.D. Mood Food; A brief look at addictive eating; In Excess; Jul 10, 2013.

[52] Martin R. Yeomans', Emma Coughlan ;Mood-induced eating. Interactive effects of restraint and tendency to overeat; Appetite; 52( 2); Pg: 290-298.,April 2009.

[53] Appleton KM, Woodside JV, Yarnell JW, Arveiler D, Haas B, Amouyel P, Montaye M, Ferrières J, Ruidavets JB, Ducimetiere P, Bingham A, Evans A.; Depressedmood and dietary fish intake: direct relationship or indirect relationship asa result of diet and lifestyle?; J Affect Disord.;104(1-3):217-23.;Dec 2007.

[54] J. Geralds, "Sega Ends Production of Dreamcast," vnunet.com, para. 2, Jan. 31, 2001. [Online]. Available: Edward Leigh Gibson' ;Emotional influences on food choice: Sensory, physiological and psychological pathways ; Physiology \& Behaviour; 89(1), Pg: 53-61, 30 August 2006.
[55] Cools, Joseph; Schotte, David E.; McNally, Richard J. Emotional arousal and overeating in restrained eaters; Journal of Abnormal Psychology, Vol 101(2), 348-351.,May 1992.

[56] Bonnie A. White, Caroline C. Horwath and Tamlin S. Conner ; Many apples a day keep the blues away - Daily experiences of negative and positive affect and food consumption in young adults ;British Journal of Health Psychology; 18, (4), pg: 782-798, November 2001.

[57] James E Gangwisch , Lauren Hale , Lorena Garcia, Dolores Malaspina, Mark G Opler, Martha E Payne, Rebecca C Rossom, and Dorothy Lane; High glycemic index diet as a risk factor for depression: analyses from the Women's Health Initiative; Am J Clin Nutr;102( 2) pp- 454-463;August 2015.

[58] Rafael T Mikolajczyk, Walid El Ansari and Annette E Maxwell Food consumption frequency and perceived stress and depressive symptoms among students in three European countries ;Nutrition Journal $; 8: 31 ; 15^{\text {th }}$ July 2009.

[59] Coppen A, Bolander-Gouaille C;Treatment of depression: time to consider folic acid and vitamin B12.;J Psychopharmacol.;19(1):59-65;Jan 2005.

[60] Amanda Geary; The Food and Mood Handbook: Find Relief at Last from Depression, Anxiety, PMS, Cravings and Mood Swings ; Chapter 2, 'Craving Balance'. Yin/Yang balance; mainmainmasakmasak.wordpress.co m, September 6, 2007 .

[61] ww.faqs.org/nutrition/Met-Obe/Mood-FoodRelationships.html

[62] https://en.wikipedia.org/wiki/Serotonin.

[63] Minati Singh; Mood, food, and obesity Department of Pediatrics, University of Iowa, Department of Pediatrics ;USA Journal .frontiersin.org; 01 September 2014.

[64] http://www.naturalnews.com/019885 nuts and seeds cognitive function.html

\section{Author Profile}

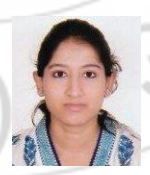

Shreyasi Halder is presently working as a research fellow under the guidance of Dr. Kazi Layla Khaled in the Department of Home Science, University of Calcutta and also pursuing BEd. course from this University. She did her post graduation in Food and Nutrition from Department of Home Science, University of Calcutta and ranked fifth in the merit list and have qualified UGC NET.

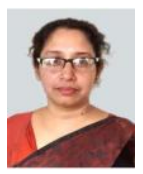

Dr. Kazi Layla Khaled ${ }^{2}$, Senior Assistant Professor is working as an Assistant Professor, Department of Home Science, University of Calcutta. Her research interests are based on different aspect of Food \& Nutrition. She is working in this University since 2003 Her works have been published in various renowned journals of Food \& Nutrition. She is presently working in the field of medicinal plants, herbs and unconventional food sources. 